\section{A MOBILIZAÇÃO ESPORTIVA PROMOVIDA PELO DEPARTAMENTO DE EDUCAÇÃO FÍSICA DO ESTADO DE SÃO PAULO NA GUERRA CIVIL DE 1932}

\begin{abstract}
THE SPORTS MOBILIZATION PROMOTED BY THE SÃO PAULO STATE DEPARTMENT OF PHYSICAL EDUCATION IN THE 1932 CIVIL WAR C
\end{abstract}

LA MOVILIZACIÓN DEPORTIVA PROMOVIDA POR EL DEPARTAMENTO DE EDUCACIÓN FÍSICA DEL ESTADO DE SÃO PAULO EN LA GUERRA CIVIL BRASILEÑA DE 1932BIBLIOMÉTRICO EN LA WEB OF SCIENCE DE 1945 A 2019 C

doi' https://doi.org/10.22456/1982-8918.101640

André Dalben*<dalben@unifesp.br>

Lucas Polli da Palma** <lucas_polli_palma@hotmail.com>

\footnotetext{
*Universidade Federal de São Paulo. Santos, SP, Brasil.

**Universidade Estadual de Londrina. Londrina, PR, Brasil.
}

Resumo: O Departamento de Educação Física do Estado de São Paulo (DEFSP) suspendeu suas atividades oficiais durante a guerra civil de 1932 e passou a recrutar esportistas para a luta armada. A pesquisa teve por objetivo descrever o envolvimento do DEF-SP na guerra, analisar as narrativas publicadas pela imprensa paulistana sobre o alistamento e a participação dos esportistas e identificar as estratégias empreendidas para a construção de uma memória para o evento. Conclui-se que o DEF-SP centralizou as ações de clubes e federações esportivas para prestar apoio à luta armada e formar três tropas paramilitares. A imprensa atribuiu valores físicos e morais ao esporte para fomentar sentimentos regionalistas entre a população e afirmar uma identidade paulista. Dois anos após o armistício, foi fundada a Associação Cívica Primeiro Batalhão Esportivo para estabelecer uma memória triunfalista ao levante armado dos esportistas.

Palavras chave: Guerra. Esportes. Memória. Identidade social.
Recebido em: 08 abr. 2020 Aprovado em: 26 abr. 2021 Publicado em: 12 jul. 2021

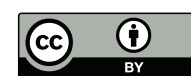

Este é um artigo publicado sob a licença Creative Commons Atribuição 4.0 Internacional (CC BY 4.0).

elSSN: 1982-8918 


\section{INTRODUÇÃO}

O Departamento de Educação Física do Estado de São Paulo (DEF-SP) iniciou oficialmente suas atividades em janeiro de 1931. A sua criação esteve ligada aos interesses de colocar São Paulo em posição de destaque frente aos demais estados no cenário esportivo nacional e estabelecer uma identidade paulista por meio do esporte. O seu objetivo de orientar, dirigir e fiscalizar a prática esportiva também perpassava por questões eugênicas de se criar uma população considerada como forte e produtiva e combater práticas corporais apreciadas como desmedidas ou imorais. Os seus cargos foram assumidos pelo engenheiro e tenista Antonio Bayma (direção), pelo advogado e cronista esportivo Américo Netto (secretário geral), pelo médico e cronista esportivo Arne Enge e pelo médico Benjamin Alves Ribeiro (inspetores técnicos) (DALBEN et al., 2019).

O DEF-SP teve suas atividades suspensas em julho de 1932 por conta dos confrontos armados originados pela autoproclamada Revolução Constitucionalista. A batalha decorreu da escalada de tensão entre lideranças políticas de São Paulo e o Governo Provisório de Getúlio Vargas. Divergências políticas, econômicas e sociais culminaram na guerra civil que se estendeu por oitenta e três dias entre combatentes do estado insurgente e exército nacional. Com o deflagrar da guerra, o DEF-SP passou a recrutar esportistas para a luta armada.

Nos estudos historiográficos perseveram duas versões opostas sobre a guerra de 1932, as quais expressam a polarização entre os discursos dos vencedores (a versão varguista) e dos vencidos (a versão paulista ou triunfalista). Na narrativa varguista predomina o desejo, por vezes separatista, das elites paulistas de recuperar a primazia política e os privilégios econômicos perdidos com a ascensão de Vargas ao poder em 1930. Já na narrativa paulista predomina o desejo pretensamente popular de recostitucionalização do país, em uma leitura que se apoia na hipótese de que as eleições de 1933 e a promulgação da Constituição de 1934 não teriam ocorrido se não fosse empreendida a guerra civil. As duas versões, expressas nos documentos históricos desde o início dos confrontos armados, perseveram até a atualidade e se imiscuem em estratégias empreendidas para a dominação da sua memória (BORGES, 1997; PAULA, 1998; SANTOS; MOTA, 2010).

A comemoração do evento e o culto aos heróis são realizados na atualidade, por exemplo, pelos vencidos e não pelos vencedores. Em São Paulo, uma série de mitos e monumentos foram construídos para a guerra civil, prevalecendo na memória local a versão triunfalista. Em 1954 (data de celebração do IV Centenário da Cidade de São Paulo) e nos anos consecutivos, diversas homenagens foram prestadas a 1932, como a fundação da Sociedade de Veteranos MMDC, inauguração do Obelisco-Mausoléu, instituição da medalha 9 de julho, publicação de suplementos especiais na imprensa, entre outras ações para tornar a narrativa paulista predominante na memória local (BORGES, 1997). A participação dos esportistas nos confrontos armados também integrou o conjunto de homenagens prestadas (TAMBÉM LUTARAM, 1954, p.4; COMEMORAÇÃO, 1958, p.2) e tem visitado, com certa frequência na última década, páginas e telas dos meios de 
comunicação, especialmente nas datas comemorativas instituídas para exaltar e reafirmar a versão paulista (REIS, 2012; ROSEGUINI; OUTEIRAL, 2018; VEIGA, 2015).

Em conjunto com as disputas pela memória de 1932, a guerra civil também exerceu papel proeminente na afirmação de uma identidade regional paulista. Segundo Weinstein (2015) e Santos e Mota (2010), durante os confrontos armados, a imprensa paulistana veiculou narrativas, fundamentadas em discursos eugênicos e teorias evolucionistas, que estabeleciam e aclamavam uma superioridade econômica, cultural, moral e racial para São Paulo, definindo-o como o arauto da modernidade em oposição ao suposto atraso dos outros estados brasileiros (especialmente das regiões Norte e Nordeste). É certo que a formação dessa identidade, marcada por uma pretensa excepcionalidade de São Paulo sobre o restante do país, era anterior a 1932 (FERRETTI, 2004), mas nesse momento ganhou novas motivações e conotações políticas. O recrutamento de novos combatentes era bradado em defesa tanto do estado quanto do país: "Tudo por São Paulo! Tudo pelo Brasil!" constituía-se como lema convocatório. Nesse sentido, regionalismo e nacionalismo não eram alocados discursivamente como opostos, mas como complementares, sendo São Paulo representado como o estado detentor das virtudes nacionais.

O recrutamento de esportistas pelo DEF-SP se apresenta como um elemento especialmente relevante na história da guerra civil de 1932, uma vez que o esporte pode ser compreendido como constitutivo de identidades nacionais e regionais, da formação de sentimento patriótico, da integração nacional, da educação cívica, entre outras especificidades extensamente estudadas pela Sociologia do Esporte (BRACHT, 2011). Ao se basear nesses pressupostos teóricos, foram estabelecidos os seguintes objetivos para a pesquisa: descrever o envolvimento do DEF-SP na guerra civil de 1932, analisar as narrativas publicadas pela imprensa paulistana sobre o alistamento e a participação dos esportistas e identificar as estratégias empreendidas para a construção de uma memória para o evento.

Segundo Capelato (1981), a imprensa paulistana é fonte privilegiada para pesquisas sobre a guerra civil de 1932, uma vez que teve papel de destaque na formulação e divulgação dos ideais paulistas. Os jornais não realizaram apenas cobertura diária dos confrontos, mas pluralizaram a mobilização para todas as camadas da sociedade. Em suas palavras: "Em 1932, todos os veículos de comunicação foram mobilizados no sentido de sensibilizar o 'povo paulista' para a "causa de São Paulo" (CAPELATO, 1981, p.32). As fontes empregadas na pesquisa foram levantadas na Hemeroteca Digital da Biblioteca Nacional e no Acervo Digital do jornal O Estado de S. Paulo. A consulta foi realizada com os termos "Batalhão Esportivo" e "Mobilização Esportiva" e se circunscreveu aos anos de 1930 a 1939. Ao todo foram levantadas 226 matérias, em sua maioria publicadas pelos jornais paulistanos A Gazeta, Correio de S. Paulo, Correio Paulistano, Diário Nacional e O Estado de S. Paulo. 


\section{RESULTADOS E DISCUSSÃO}

\subsection{ALISTAMENTO ESPORTIVO}

Uma semana após o início do levante armado em 9 de julho de 1932, a imprensa começou a anunciar as movimentações empreendidas pelos DEF-SP para efetivar o alistamento de combatentes na sua organização paramilitar, denominada inicialmente como Batalhão Constitucionalista de Esportistas Paulistas. Convocações eram feitas diretamente aos atletas e sócios de clubes para que ingressassem no pelotão ou para que se transferissem para ele no caso de já estarem inscritos em outros. Bayma visitou pessoalmente a sede dos clubes paulistanos para verificar como seus dirigentes estavam se mobilizando para recrutar voluntários. Américo Netto viajou a Santos para coordenar as ações dos clubes locais. O secretário estadual da educação e da saúde pública nomeou 25 representantes no interior do estado para organizar o alistamento de esportistas e embarcá-los para a capital. A Federação Paulista de Atletismo estabeleceu contato com seus clubes filiados e representantes espalhados em 28 cidades. A Associação Paulista de Esportes Atléticos (APEA) atuou de forma semelhante (A MOBILIZAÇÃO, 1932a; MOBILIZAÇÃO, 1932a; MOBILIZAÇÃO, 1932b). Todas as ações empreendidas pelos clubes, federações e órgãos da administração pública visavam viabilizar a formação de um batalhão formado apenas por esportistas. Ao DEF-SP caberia, além de coordenar o recrutamento dos voluntários, disponibilizar transporte, alojamento, instrução militar, equipamentos, uniformes, armas e munições (MOBILISAÇÃO, 1932b).

Diversos foram os clubes que atenderam a mobilização. O São Paulo Futebol Clube forneceu seu campo de futebol para o preparo militar dos esportistas. O clube Palestra Itália disponibilizou todas suas instalações, além de realizar doações. A Sociedade Hípica Paulista criou posto destinado a costurar fardas. O Clube Atlético Paulistano estabeleceu alistamento para mulheres, para que fossem designadas ao corpo de saúde da Cruz Vermelha (MOBILIZAÇÃO, 1932a). Na imprensa, palavras de estímulo eram veiculadas: "Todos os clubes náuticos e futebolísticos tem contribuído com grande parcela em apoio a causa que São Paulo abraçou, contanto com a abnegação infalível de todos os seus filhos" (A MOBILIZAÇÃO, 1932c, p.3). Ao longo da guerra, foram contabilizados pelas fontes levantadas 59 clubes e entidades esportivas paulistas que contribuíram com a inscrição de voluntários, arrecadação de donativos ou a cessão de seus espaços e materiais.

Além dos jornais, o rádio foi outro meio de comunicação utilizado para convocar esportistas. Em pronunciamento, Bayma qualificava o alistamento dos atletas como emblema de civismo e definia a mobilização coordenada pelo DEF-SP como prova de haver no esporte "uma grandeza moral a altura de sua eficiência técnica" (MOBILISAÇÃO, 1932b, p.4). Pronunciamentos específicos eram realizados para que esportistas do interior paulista também se juntassem à mobilização iniciada na capital. O discurso do representante da APEA, por exemplo, se valia de sentimentos nacionalistas e regionalistas para promover a união dos esportistas: "[...] é como brasileiro, como paulista e como esportista, fardado como os demais e pronto para a partida que eu venho lhes fazer este convite, para que todos reunidos no Batalhão 
Esportivo marchemos para a luta, pela honra de São Paulo, pela glória do Brasil!" (A MOBILIZAÇÃO, 1932d, p.3).

Segundo Capelato (1981), era comum que apelos fossem feitos por categorias profissionais, como engenheiros, advogados, médicos etc., as quais respondiam com a organização de batalhões específicos. A imprensa conferia prestígio à criação dessas organizações e incentivava os alistamentos com bordões como "Você tem dever a cumprir" e "Consulte a sua consciência". No caso dos esportistas, veiculava bordões como "o esporte é a base da energia! Tudo pelo Brasil unido!" (MOBILISAÇÃO, 1932b, p.4). A aclamação atrelava a adesão dos esportistas ao vigor, ou seja, a energia era concebida tanto como um atributo físico quanto uma virtude moral inerente ao esportista que se voluntariava para a guerra. A Rádio Sociedade Record organizou programa destinado a homenagear os esportistas que seguiam para as linhas de frente, com a presença de representantes de entidades esportivas e do DEF-SP. A rádio afirmou que: "Nesta hora sagrada, o esporte não é apenas uma maravilhosa máquina de aperfeiçoamento físico. É a barreira sólida, intransponível, da honra paulista, da honra de todo Brasil" (MOBILIZAÇÃO, 1932k, p.2).

O esporte não pode ser considerado como uma simples categoria profissional, até mesmo porque nesse momento prevalecia intensa disputa entre os ditames do amadorismo e do profissionalismo no seio das federações e clubes. Como se percebe pelos pronunciamentos, o valor do esporte para a guerra também não se resumia à formação de corpos fortes e ágeis. Valores morais como honra, coragem, lealdade e espírito de equipe se sobressaíam nos discursos e incitavam a coesão dos esportistas a favor da guerra. Ao seguirem para a capital, os atletas do Santos Futebol Clube, por exemplo, deixaram aos moradores da cidade carta na qual afirmavam que todas as bandeiras dos clubes paulistas se reuniriam por uma única causa, ou seja, um único time seria formado no Batalhão Esportivo, o time do estado de São Paulo em defesa do Brasil.

O mesmo trem que nos conduziu a $\mathrm{S}$. Paulo tantas vezes para defendermos esportivamente o nome do nosso querido clube, agora nos conduz, também, mas desta vez a missão é mais grave e honrosa. Vamos defender a bandeira da Liberdade que nosso Estado levantou em benefício de todos os brasileiros e para Honra e Gloria do nosso Brasil. Adeus companheiros de Santos e do Santos F. C., os que ficam, si nossa terra for invadida a defendam com o amor que vamos defender S. Paulo e o Brasil. (MOBILIZAÇÃO, 1932c, p.2)

De acordo com Hobsbawm (1990), o esporte exerce um papel proeminente na conformação de identidades nacionais, sendo comum, por exemplo, que rivalidades entre nações sejam transferidas para disputas esportivas. No caso específico da guerra civil de 1932, a alegoria construída não representava necessariamente uma disputa entre São Paulo e o Brasil, mas um sacrifício dos paulistas em nome do país. Isto é, não se tratava de um embate entre a identidade regional e a nacional, mas da alusão a uma identidade paulista que transcenderia as fronteiras regionais e passava a representar ela mesma a maior grandeza da nação. Metáforas entre o esporte e a guerra eram estabelecidas e alusões aos bandeirantes eram feitas no jornais, transformando-os em símbolo de heroísmo não apenas paulista, mas nacional. 
Partem [os esportistas] todos cheios de fé e confiantes na vitória com aquele mesmo desprendimento com que partiam os paulistas de outrora, na luta pela grandeza da lendário $\mathrm{S}$. Paulo de Piratininga, no século memorável das bandeiras, que levaram para bem longe as fronteiras deste nosso grandioso Estado. Vivem ainda em nosso céu os clarões daquelas conquistas, que tiveram como cenário as regiões longínquas do Sul até Guaíra e pelo norte os vastos territórios que iam da Amazônia misteriosa até as praias do Pacífico, também batidas pelo tacão da bota do paulista audaz. Novamente por São Paulo e pelo Brasil partem os bandeirantes modernos, sentindo n'alma a mesma coragem para luta e no peito a vontade férrea de vencer. [...] Esportistas de S. Paulo, o vosso traje agora deve ser o do soldado, para demonstrardes o vosso amor por esta grande terra que tantas vezes honrastes condignamente no campo do esporte. Honrai a bandeira e o nome do vosso clube, empunhando uma arma e partindo resolutos para as trincheiras. (A MOBILIZAÇÃO, 1932c, p.3)

O jogador de futebol de maior destaque da época, Arthur Friedenreich foi eleito como orador da mobilização. Em discurso na rádio, lembrava os ouvintes de sua famosa atuação nos gramados nacionais, sul-americanos e europeus para se afirmar como exemplo a ser seguido. Recorreu aos supostos valores físicos e morais do esporte ao dizer sentir "a energia física e moral que todos vós, também esportistas, certamente sentis" (FRIEDENREICH, 1932, p.1). Seu objetivo era estimular colegas a seguirem seus passos e também se alistassem no batalhão criado pelo DEF-SP. Após o pronunciamento no rádio, Friedenreich viajou para cidades do interior paulista para continuar a divulgação da mobilização esportiva (PROSSEGUE, 1932).

Atuante em diversos clubes paulistanos, Friedenreich ganhou notoriedade ao integrar o selecionado brasileiro convocado para disputar o Campeonato Sul-Americano de Futebol de 1919, realizado no Rio de Janeiro, e marcar o gol da partida final, garantindo a vitória brasileira. O sucesso do desempenho na competição acompanhou a grande comoção despertada nos moradores do Rio de Janeiro e de São Paulo, sendo os campeões recebidos pelo presidente e tendo inúmeros jornais estampado a fotografia de Friedenreich em suas páginas. O primeiro título de expressão internacional conquistado no futebol foi noticiado pelo jornal Correio Paulistano, em tons triunfalistas e regionalistas, como fruto da superioridade dos jogadores paulistas. Para Gonçalves Junior (2008), a ocasião não apenas consolidou Friedenreich como o primeiro ídolo esportivo brasileiro, como teve grande relevância para afirmar o futebol como uma prática cultural central na formação da identidade nacional, assim como da identidade paulista. Na crônica futebolística, São Paulo era apresentado como responsável pela vitória brasileira; uma representação muito próxima daquela que seria construída pelos paulistas para a guerra civil de 1932, ou seja, de uma luta encetada pelo estado de São Paulo para a vitória do Brasil.

De acordo com Bracht (2011), o esporte tende a promover a identificação da população com um coletivo por meio da categoria nação. Tal categoria apresenta forte viés cultural e político, atuando diretamente no emotivo, sem que haja a necessita de explicação racional do conceito nação para que haja a identificação da população. Segundo Sevcenko (1992), Friedenreich, junto com outros esportistas, foi uma figura constante nos jornais paulistanos da década de 1920. Esses atletas 
"[...] despertavam em seus admiradores, quaisquer que fossem suas etnias, nacionalidades, condição social, sexo ou convicções, uma nova identidade e um peculiar orgulho compulsivo de se sentir parte da cidade" (SEVCENKO, 1992, p.57). Essa emoção despertada pelos esportes e pela admiração aos atletas foi empregada como forma de construir um sentimento de pertencimento a causa comum e de participação em uma comunidade imaginada. De acordo com Anderson (2008), o sentimento de inserção dentro de uma comunidade se deve à intrínseca relação entre os indivíduos no desenhar de uma imagem viva de comunhão. Nesse sentido, o protagonismo de Friedenreich na mobilização esportiva pode ser considerado como estratégia de promoção de uma comunidade que se compreende como única, neste caso, de uma identidade regional paulista.

O pronunciamento realizado por Friedenreich no rádio foi replicado pelos principais jornais paulistanos. O jogador iniciou dentro do Batalhão Esportivo com posição de destaque, no posto de segundo sargento e, após os primeiros confrontos armados, foi promovido para segundo tenente. Na imprensa houve aqueles que reclamaram dele já não ter partido de São Paulo com patente maior (O PRIMEIRO, 1932). A promoção concedida, além de responder às reclamações, foi anunciada na imprensa como decorrência dos seus atos de bravura na guerra. Seu nome voltava, assim, a estampar as manchetes dos jornais como herói paulista (MOBILIZAÇÃO, 1932h).

Quase um mês após o início da mobilização do DEF-SP, os jornais anunciavam a completa formação do primeiro Batalhão Esportivo, com cerca de 900 combatentes provenientes de aproximadamente 47 clubes da capital e do interior paulista (MOBILISAÇÃO, 1932a; MOBILIZAÇÃO, 1932d). Ao longo desse período, os esportistas receberam instruções militares diárias no campo do São Paulo Futebol Clube. No dia 2 de agosto, após solenidades, o pelotão seguiu para as trincheiras em Eleutério, distrito de Itapira, na divisa entre São Paulo e Minas Gerais (O BATALHÃO, 1932a). Enge o acompanhou como capitão médico do seu corpo de saúde, enquanto Bayma, nomeado major, e Américo Netto, nomeado capitão, permaneceram na capital para organizar o próximo batalhão e as atividades de retaguarda (MOBILIZAÇÃO, 1932e). Eventualmente Bayma ia aos campos de batalha para distribuir materiais arrecadados e verificar o estado das tropas (A MOBILIZAÇÃO, 1932b; O $1^{\circ}$ BATALHÃO, 1932).

Importante ressaltar, como analisado por Paula (1998), que a guerra civil de 1932 foi também uma guerra de imagens. Fotografias de diversos esportistas figuraram nas páginas dos jornais, especialmente no momento da convocação para o alistamento de voluntários. Imagens de Friedenreich eram dispostas em conjunto com as de outras figuras esportivas do momento, como Luizinho e Luiz Araripe Sucupira (A JUVENTUDE, 1932). Fotografias da solenidade de partida do primeiro Batalhão Esportivo estamparam a capa do jornal Diário Nacional com os dizeres: "os bravos voluntários desfilam pela cidade" (O PRIMEIRO, 1932, p.1). 
Ilustração 1 - Desfile do Batalhão Esportivo em São Paulo

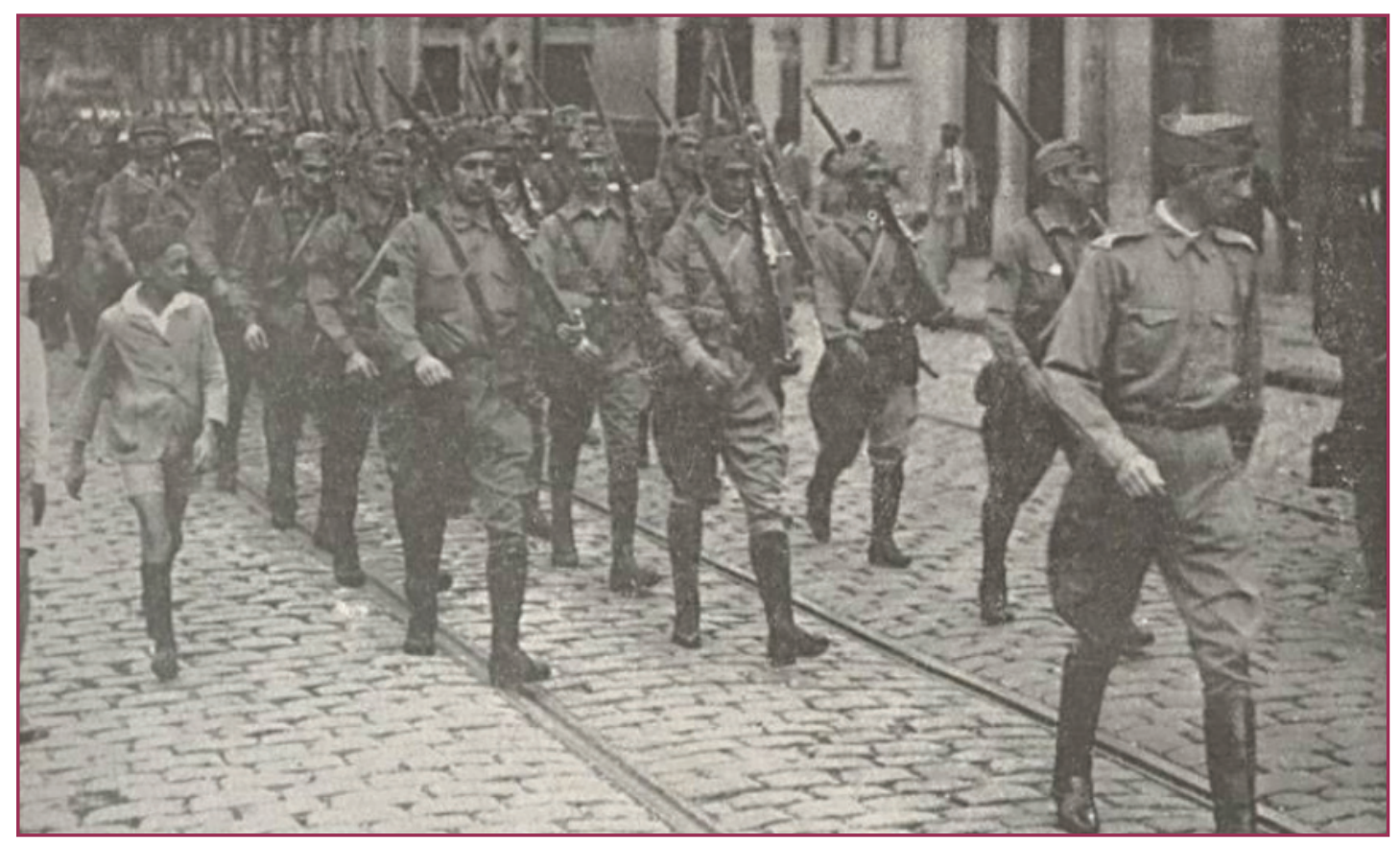

Fonte: PÁGINAS, 1932, p.22.

A revista feminina $A$ Cigarra também publicou a fotografia do alinhado batalhão em desfile pelas ruas do centro de São Paulo e com um garoto seguindo os seus ídolos esportivos, agora transformados em combatentes fardados e armados (llustração 1). A fotografia fora cortada, na original (PAULA, 1998, p.142) aparecem outros três garotos no canto esquerdo, um deles inclusive segurando uma bola de futebol, mas com vestimentas mais simples, denunciando sua classe social. É possível que outros periódicos também a tenham publicado para sensibilizar a população à causa paulista, dado seu forte simbolismo imagético. Outra função das fotografias era a de provar que os integrantes do Batalhão Esportivo passavam bem após cada confronto ocorrido nas trincheiras. Nos jornais eram publicadas fotografias posadas, com rostos sorridentes e presença constante de Friedenreich (O BATALHÃO, 1932b; MOBILIZAÇÃO, 1932I).

$\mathrm{Na}$ imprensa paulistana e carioca uma guerra de desinformação foi também travada. Dias depois da partida de Friedenreich para o campo de batalha, o jornal carioca $A$ Vanguarda publicou matéria falsa anunciando a morte do ídolo futebolístico. A informação enganosa chegou a ser replicada na imprensa argentina e uruguaia. O jornal paulistano A Gazeta denunciou a mentira e aproveitou para desmoralizar as forças varguistas e vangloriar os combatentes paulistas. Dois dias depois, Friedenreich foi promovido para primeiro tenente e voltou a estampar as páginas dos jornais (OUTRA MENTIRA, 1932; VEIO, 1932; COMO ECOOU, 1932).

\subsection{RETAGUARDA}

Logo após a partida do primeiro Batalhão Esportivo, o DEF-SP aderiu à campanha destinada a angariar fundos para fabricação de capacetes de aço e armas. Uma reunião foi organizada com representantes das entidades esportivas e 
clubes com o intuito de promover a arrecadação de medalhas e troféus. A ação foi desenvolvida em prol da Campanha do Ouro, organizada pela Associação Comercial de São Paulo. Bayma ofereceu suas medalhas conquistadas no tênis. Américo Netto doou suas conquistas do automobilismo. Max de Barros Erhart, presidente da APEA, e seu irmão, Renato de Barros Erhart, entregaram 60 medalhas (MOBILIZAÇÃO, 1932g; MOBILIZAÇÃO, 1932j). Na imprensa, as doações eram qualificadas como atos virtuosos para encorajar outros esportistas a seguirem os exemplos. Por meio das arrecadações, medalhas comemorativas eram produzidas para serem vendidas na secretaria do DEF-SP e o valor arrecadado era destinado principalmente para compra de capacetes (200 MEDALHAS, 1932). Houve clube que doou todas as medalhas e troféus, como o caso do Tiradentes Futebol Clube (MOBILIZAÇÃO, 1932i). E ainda o caso do Clube Athletico Paulistano, frequentado pela elite paulistana e que, próximo ao fim da guerra, realizou depósito em dinheiro junto ao Banco Comercial e Industrial de São Paulo para resgatar seus troféus entregues à Campanha do Ouro (MOBILIZAÇÃO, 1932m). Recuperadas ou não, as doações eram vangloriadas pelos jornais como mais uma contribuição honrosa dos esportistas a favor de São Paulo. Esporte e valores morais eram novamente entrelaçados no discurso da imprensa paulistana.

Para viabilizar comunicação entre esportistas-combatentes e seus familiares, 0 DEF-SP criou o Correio Militar Esportivo (MOBILIZAÇÃO, 1932f). A entrega das cartas na capital era realizada por crianças do grupo escoteiro ACruzada (ACOLABORAÇÃO, 1932). O jornal A Gazeta criou seu próprio correio militar, destinando parte de seu editorial diário para a troca de cartas entre familiares e combatentes, inclusive os do Batalhão Esportivo (CORREIO, 1932). Segundo Capelato (1981), a comunicação era fiscalizada para que não fossem divulgadas informações depreciativas sobre os combates, pois havia receio de que novas adesões fossem desmotivadas. Este controle selecionava as cartas que narravam atos heroicos para serem transcritas nos jornais e gerarem comoção popular.

\subsection{CAMPO DE BATALHA}

Uma das cartas publicadas pela $A$ Gazeta estabeleceu narrativa triunfalista para a primeira batalha enfrentada pelo Batalhão Esportivo em Eleutério no dia 5 de agosto. No batismo de fogo, que perdurou por três dias, teriam os combatentes paulistas respondido na mesma medida aos canhões, metralhadoras, fuzis e aviões do exército nacional. A narrativa se deteve no elemento surpresa da locomotiva com vagões encobertos de chapas de aço, chamado de "trem blindado", e na fuga desesperada dos inimigos (COMO SE DEU, 1932). Apesar da batalha ter sido de fato vitoriosa para os paulistas, segundo os documentos analisados por Apolinário (2018), o trem mais gerava rumores e lendas do que se provava eficaz, uma vez que suas chapas não garantiam completa proteção. Não obstante, era extensamente explorado pela imprensa paulistana como a "besta metálica" ou "fantasma da morte".

Nos relatos dos esportistas-combatentes publicados nos jornais, narrativas de bravura eram constantes. Batalhas vitoriosas eram veneradas, omitindo-se derrotas. A atuação do primeiro Batalhão Esportivo era elogiada como desassombrada e 
seus recuos atenuados como "retiradas estratégicas" (O BATALHÃO, 1932c). A desproporção de forças entre exército nacional e tropas paulistas, no entanto, era enorme. Cabe também ressaltar que "por se tratarem de atletas, alguns muito jovens, a grande maioria nunca havia pegado em fuzil ou qualquer tipo de armas. O treinamento durou pouco tempo, apenas para se acostumarem com o peso da farda e o fuzil e ter algumas noções de tiro" (APOLINÁRIO, 2018, p.36). Recrutas do segundo Batalhão Esportivo tiveram ainda menos dias de treinamento do que seus colegas do primeiro pelotão e foram enviados a cidade de Itapira sem tempo para solenidades ou desfiles (A BANDEIRA, 1932). Lá provavelmente se encontraram com os colegas que haviam recuado do distrito de Eleutério, já ocupado pelos soldados do exército nacional desde final do mês de agosto.

Conforme as tropas nacionais avançavam, novos combatentes eram recrutados com urgência nas cidades do interior paulista e enviados para os campos de batalha. Esse conjunto de voluntários foi denominado como o terceiro Batalhão Esportivo (PARTIU, 1932). Segundo relatos, era comum que tropas recebessem "seus fuzis já nas cidades em que iriam combater, praticamente a poucos metros das trincheiras" (APOLINÁRIO, 2018, p.153). Em setembro, o primeiro Batalhão Esportivo regressou à capital paulista por ordem superior, mas poucos dias depois foram novamente recrutados para a linha de frente. Aqueles que não se apresentassem eram ameaçados de terem seus nomes publicados como desertores (REGIMENTO, 1932). Comentários contrários às narrativas triunfalistas, que eventualmente circulavam entre a população, eram combatidos nos jornais com a publicação das palavras de esportistas sobre o valor de sua honra e de seus feitos na guerra (MOBILIZAÇÃO, 1932I). Segundo noticiário, cerca de 1.500 voluntários se inscreveram na mobilização esportiva coordenada pelo DEF-SP. Civis não esportistas também compuseram os três batalhões organizados. "Após as quedas de Eleutério e Itapira, o $1^{\circ}$ e $\circ 3^{\circ}$ Batalhão Esportivo, seguiram para a Frente Sul” (APOLINÁRIO, 2018, p.33). Ainda que a formação do quarto Batalhão Esportivo tivesse sido iniciada, não chegou a ir a campo de batalha devido ao fim da guerra em outubro (MOBILIZAÇÃO, 1932m; VOLUNTÁRIOS, 1932).

\subsection{CESSAR-FOGO}

Após o armistício, a imprensa voltou a publicar as práticas esportivas realizadas cotidianamente na capital. O paradeiro de alguns esportistas era, porém, desconhecido. Esse foi o caso do "Onça", jogador do Esporte Clube Corinthians, e do "Feitiço", do Santos Futebol Clube, conforme relatado por jornal paranaense (DESCONHECIDO, 1932). Durante a guerra foi anunciado que não tinha ocorrido nenhuma baixa no primeiro Batalhão Esportivo (NÃO HOUVE, 1932). A primeira nota de falecimento foi divulgada já próxima ao final dos confrontos (HEROES, 1932). Foi somente após o armistício que começaram a aparecer mais informações sobre esportistas falecidos ou desaparecidos (CORREIO, 1932; NECROLOGIA, 1932; OS DESAPARECIDOS, 1932; FALLECIMENTOS, 1932). O conjunto de notícias posteriores à rendição de São Paulo, evidenciam, segundo Capelato (1981), o papel exercido pela imprensa como reguladora das informações a serem reveladas a 
população e como responsável pela construção dos ideais da causa paulista, sendo a maioria das baixas publicada somente depois do cessar-fogo. Ao menos quatro esportistas integrantes do primeiro Batalhão Esportivo foram mortos durante as batalhas (HOMENAGEM, 1934a), mas, conforme revelado por Apolinário (2018), é possível que outros combatentes tenham sido enterrados pelas estradas e trincheiras da região de Itapira. Passados seis anos, ainda havia mãe procurando por seu filho, ex-combatente do Batalhão Esportivo (DESAPARECIDO, 1938).

Dias depois do cessar-fogo, integrantes do primeiro Batalhão Esportivo procuraram o jornal $A$ Gazeta a fim de que fossem publicados seus descontentamentos com o DEF-SP devido à falta de pagamento dos seus honorários pelo engajamento no levante armado (OS VOLUNTÁRIOS, 1932). A informação demonstra haver insatisfação por parte de voluntários do Batalhão Esportivo e que retribuição financeira foi oferecida para a participação de alguns deles na mobilização. É significativo também o receio de esportistas não obedecerem às ordens superiores, emitidas pouco antes do final da guerra, para que retornassem aos campos de batalhas, sendo ameaçados de terem seus nomes publicados como desertores, como descrito anteriormente. Apesar de indícios que contrariam a narrativa sempre ufanista, virtuosa e heroica formulada pela imprensa paulistana, após o armistício prevaleceram movimentações para construção de um ideal de vitória, mesmo que esta não tenha efetivamente ocorrido. Criou-se uma percepção de vitória moral por ato de bravura e em prol da construção de um legado memorável para São Paulo.

Em 1933, esportistas do primeiro Batalhão Esportivo foram convidados para visitarem os locais nos quais combateram: Eleutério, Fazenda Amarela, Bento Cunha, Santa Joanna e Barão Ataliba (1BATALHÃO, 1933). Em 18 de junho de 1934, na sede da Associação Atlética São Paulo, foi criada a Associação Cívica Primeiro Batalhão Esportivo (ACPBE) (FUNDOU-SE, 1934). Diversos rituais foram empreendidos naquele ano: instituição dos dias 4 e 5 de julho como comemorativos do batismo de fogo do primeiro Batalhão Esportivo, dedicação de missas aos falecidos em combate e idas aos locais de sepultamento para homenagens (ASSOCIAÇÃO, 1934). O Clube Esperia inaugurou "placa comemorativa ao feito dos heróis que tombaram" (HOMENAGEM, 1934b, p.4) e realizou sessão solene para seus sócios mortos em combate, alguns dos quais recrutados pelo Batalhão Esportivo. O Clube de Regatas Tietê também inaugurou "lápide comemorativa do feito dos seus associados mortos" (9 DE JULHO, 1936, p.16).

Mais do que simples homenagens, tratava-se de rituais para venerar a memória dos mortos e buscar construir um símbolo de heroísmo, colaborando para a transição do sentimento de luto para o de conquista, vitória. Anderson (2008) afirma não existir símbolo maior do nacionalismo do que monumentos e túmulos de soldados reverenciados em cerimonias públicas. A data de 9 de julho tornou-se símbolo da identidade paulista, sendo comemorada nos anos subsequentes com desfile pela cidade, missas e outros ritos para revenerar a guerra de 1932 e que constantemente contavam com a presença de integrantes da ACPBE (10 BATALHÃO, 1934; COMO SERÁ, 1935; COMEMORAÇÕES, 1936). A criação de tais associações pode ser compreendida como uma maneira de imortalizar a participação dos voluntários no 
levante armado e de conservar os ideais que o movimento criou durante da guerra. A valorização das batalhas e a continuidade na narrativa triunfalista estabelecidas por essas associações permitiram a construção de um sentimento heroico com o passado, estabelecendo a guerra civil de 1932 como marco da identidade paulista.

\section{CONCLUSÃO}

Ao longo da guerra civil de 1932, o DEF-SP coordenou ações visando recrutar esportistas, fornecer preparo militar e enviá-los às trincheiras. Cerca de 1.500 combatentes (nem todos esportistas) atuaram nas três organizações paramilitares criadas. A mais bem estruturada e preparada foi o primeiro Batalhão Esportivo, sendo as outras duas compostas já no calor das batalhas. O DEF-SP também atuou na arrecadação de metais preciosos para a Campanha do Ouro e na organização do Correio Militar Esportivo. Suas ações só foram possíveis graça à intensa colaboração de clubes e federações, responsáveis pelos alistamentos dos combatentes e por reunirem voluntários para executar os mais diversos serviços, além dos inúmeros materiais doados. Ao menos 59 clubes e entidades esportivas contribuíram com a guerra.

O poder mobilizador que o esporte tinha alcançado nas últimas décadas em São Paulo foi intensamente arregimentado a favor da guerra. A adesão e atuação dos esportistas mais afamados e das lideranças de clubes e federações eram anunciadas na imprensa como exemplos a serem seguidos. Nas páginas dos jornais, em suas manchetes e fotografias, assim como nas locuções das rádios, Friedenreich figurou como orador dos esportistas-combatentes e, de ídolo esportivo, passou a ser aclamado também como herói de guerra. Ainda que o futebol passasse por um momento de ascensão no país, a participação de seus jogadores mais conhecidos o afirmaria como constitutivo de tensões entre a identidade nacional e a regional. A adesão dos esportistas era exaltada na imprensa para acender o orgulho de se lutar por uma causa nomeada como paulista e em favor do Brasil. Em discursos carregados de tons regionalistas e nacionalistas, o esporte e seus representantes se transformavam em uma das maiores grandezas de São Paulo. O valor do esporte não se resumia à capacidade de formar corpos fortes, vigorosos e ágeis. Na imprensa eram ovacionados atributos morais supostamente inerentes à prática esportiva, como honra, bravura e lealdade. A paixão esportiva se entrelaçava ao sentimento ufanista de se sentir parte de uma comunidade imaginada como excepcional. Em suma, o esporte se afirmava como parte integrante da identidade regional paulista para encorajar o levante armado.

Nos anos após a rendição de São Paulo, fez-se presente a preocupação de não se deixar transparecer o sentimento de derrota, tendo os esportistas, agora ex-combatentes, participado de desfiles, missas e visitas aos locais de batalha e de sepultamento, cerimônias organizadas pela ACPBE e pelos clubes. O poder mobilizador do esporte foi novamente arregimentado para comover a população a reverenciar aqueles que combateram na guerra. Nos anos subsequentes ao armistício procurou-se construir um ideal de vitória, ainda que esta não tenha ocorrido, por meio da inauguração de monumentos e da criação de associações de ex- 
combatentes, responsáveis por instaurar ritos comemorativos que construíssem uma memória triunfalista e inventassem uma tradição para a autoproclamada Revolução Constitucionalista.

\section{REFERÊNCIAS}

9 DE JULHO e o Tieté - São Paulo. Correio do Paulistano, São Paulo, p.16, 12 jul. 1936.

200 MEDALHAS. A Gazeta, São Paulo, p.3, 09 ago. 1932.

1 BATALHÃO Esportivo. A Gazeta, São Paulo, p.2, 25 set. 1933.

$1^{\circ}$ BATALHÃO Esportivo. Correio do Paulistano, São Paulo, p.12, 01 jul. 1934.

ANDERSON, Benedict. Comunidades imaginadas. São Paulo: Companhia das Letras, 2008. APOLINÁRIO, Eric Lucian. Inverno escarlate: 1932 vida e morte nas trincheiras do front leste. São Paulo: Gregory, 2018.

ASSOCIAÇÃO Cívica $1^{\circ}$ Batalhão Esportivo. Correio do Paulistano, São Paulo, p.11, 27 jul. 1934.

A BANDEIRA do $2^{\circ}$ Batalhão Esportivo. Correio de S. Paulo, São Paulo, p.2, 08 set. 1932.

O BATALHÃO Esportivo nos campos de Eleutério. A Gazeta, São Paulo, p.4, 16 ago. 1932b.

O BATALHÃO esportivo recebeu ontem a bandeira e parte hoje para o "front". Correio de S. Paulo, São Paulo, p.4, 02 ago. 1932a.

O BATALHÃO Esportivo teve desassombrada actuação nos combates em que tomou parte no sector Leste. Diário Nacional, São Paulo, p.4, 22 set. 1932c.

BORGES, Vavy Pacheco. Memória paulista. São Paulo: EDUSP, 1997.

BRACHT, Valter. Sociologia crítica do esporte: uma introdução. 4.ed. ljuí: Unijuí, 2011.

CAPELATO, Maria Helena. O movimento de 1932: a causa paulista. São Paulo:

Brasiliense, 1981.

A COLABORAÇÃO dos escoteiros. O Estado de S. Paulo, São Paulo, p.4, 05 ago. 1932.

COMEMORAÇÃO do 9 de julho: hoje o sepultamento dos despojos dos heróis de 1932.

Diário da Noite, São Paulo, p.2, 09 jul. 1958.

COMEMORAÇÕES 9 julho. Correio do Paulistano, São Paulo, p.03, 12 maio 1936.

COMO ECOOU na Argentina a falsa notícia de Friedenreich. A Gazeta, São Paulo, p.6, 22 out. 1932.

COMO SE DEU o baptismo de fogo do Batalhão Esportivo. A Gazeta, São Paulo, p.3, 14 ago. 1932.

COMO SERÁ comemorado o 9 de julho. Correio do Paulistano, São Paulo, p.01, 19 jun. 1935. 
CORREIO militar. A Gazeta, São Paulo, p.3, 19 out. 1932.

DALBEN, André; GÓIS JUNIOR, Edivaldo; LIMA, Rodrigo Jeronimo Correa; PALMA, Lucas Polli da. Criação do Departamento de Educação Física do Estado de São Paulo (19251932). Caderno de Pesquisa, v.49, n.171, p.264-286, jan./mar. 2019. Disponível em: https:// doi.org/10.1590/198053145203. Acesso em: 05 abr. 2020.

DESAPARECIDO. Correio do Paulistano, São Paulo, p.12, 01 fev. 1938.

OS DESAPARECIDOS. A Gazeta, São Paulo, p.5, 28 out. 1932.

DESCONHECIDO os Paradeiros de Onça e Feitiço. Correio do Paraná, Paraná, p.5, 15 out. 1932.

FALLECIMENTOS. O Estado de S. Paulo, São Paulo, p.3, 12 out. 1932.

FERRETTI, Danilo José Zioni. A construção da paulistanidade: identidade, historiografia e política em São Paulo (1856-1930). Tese (Doutorado em História Social) - Universidade de São Paulo, São Paulo. 2004.

FRIEDENREICH concita os esportistas a se alistarem. Correio de S. Paulo, São Paulo, p.1, 19 jul. 1932.

FUNDOU-SE a Associação Cívica do Primeiro Batalhão Esportivo. Correio de S. Paulo, São Paulo, p.5, 21 jun. 1934.

GONÇALVES JUNIOR, René Duarte. Friedenreich e a reinvenção de São Paulo: o futebol e a vitória na fundação da metrópole. Dissertação (Mestrado em História) - Universidade de São Paulo, São Paulo, 2008.

HEROES que tombam no campo de lucta. A Gazeta, São Paulo, p.2, 21 set. 1932.

HOBSBAWM, Eric J. Nações e nacionalismo: desde 1780. São Paulo: Paz e Terra, 1990.

HOMENAGEM aos mortos do $1^{\circ}$ batalhão esportivo. Correio de S. Paulo, São Paulo, p.1, 04 ago. 1934a.

HOMENAGEM do Esperia a seus mortos. Correio de S. Paulo, São Paulo, p.4, 11 jul. 1934b.

A JUVENTUDE esportiva do Estado de S. Paulo continua se alistando. Diário Nacional, São Paulo, p.1, 20 jul. 1932.

MOBILISAÇÃO Esportiva. O Estado de S. Paulo, São Paulo, p.2, 28 jul. 1932a.

MOBILISAÇÃO Esportiva. O Estado de S. Paulo, São Paulo, p.4, 22 jul. $1932 b$.

A MOBILIZAÇÃO da mocidade esportiva de São Paulo em prol da Constituição. Correio de S. Paulo, São Paulo, p.3, 16 jul. 1932a.

A MOBILIZAÇÃO Esportiva. Correio de S. Paulo, São Paulo, p.3, 23 jul. 1932d.

MOBILIZAÇÃO Esportiva. Correio de S. Paulo, São Paulo, p.2, 01 ago. 1932e.

MOBILIZAÇÃO Esportiva. Diário Nacional, São Paulo, p.2, 30 jul. 1932d.

MOBILIZAÇÃO Esportiva. Diário Nacional, São Paulo, p.4, 05 ago. 1932f.

MOBILIZAÇÃO esportiva. A Gazeta, São Paulo, p.2, 16 jul. 1932a. 
MOBILIZAÇÃO esportiva. A Gazeta, São Paulo, p.3, 19 jul. 1932b.

MOBILIZAÇÃO esportiva. A Gazeta, São Paulo, p.2, 21 jul. 1932c.

MOBILIZAÇÃO esportiva. A Gazeta, São Paulo, p.2, 08 ago. 1932g.

MOBILIZAÇÃO esportiva. A Gazeta, São Paulo, p.1, 13 ago. 1932h.

MOBILIZAÇÃO esportiva. A Gazeta, São Paulo, p.2, 18 ago. 1932i.

MOBILIZAÇÃO esportiva. A Gazeta, São Paulo, p.2, 03 set. 1932j.

MOBILIZAÇÃO esportiva. A Gazeta, São Paulo, p.2, 04 set. 1932k.

MOBILIZAÇÃO esportiva. A Gazeta, São Paulo, p.3, 21 set. 1932I.

MOBILIZAÇÃO esportiva. A Gazeta, São Paulo, p.3, 29 set. 1932m.

A MOBILIZAÇÃO esportiva conta com 1.480 voluntários. Correio de S. Paulo, São Paulo, p.2, 12 ago. $1932 b$.

A MOBILIZAÇÃO esportiva continua no meio do maior entusiasmo. Correio de S. Paulo, São Paulo, p.3, 19 jul. 1932c.

NÃO HOUVE nenhuma baixa no batalhão esportivo. Diário Nacional, São Paulo, p.3, 17 set. 1932.

NECROLOGIA. Correio de S. Paulo, São Paulo, p.2, 06 out. 1932.

OUTRA MENTIRA da Dictadura! A Gazeta, São Paulo, p.1, 24 ago. 1932.

O 1ํ BATALHÃO está no "front" de Minas. Correio de S. Paulo, São Paulo, p.2, 03 set. 1932.

O PRIMEIRO batalhão dos esportistas seguirá para o front. Diário Nacional, São Paulo, p.1, 02 ago. 1932.

PÁGINAS da nossa história. A Cigarra, Rio de Janeiro, p. 22, ago. 1932.

PARTIU a $1^{\text {a }}$ Companhia do $3^{\circ}$ Batalhão Esportivo. Correio de S. Paulo, São Paulo, p.3, 13 set. 1932.

PAULA, Jeziel de. 1932: imagens construindo a história. Campinas: Editora da Unicamp; Piracicaba: Editora da Unimep, 1998.

PROSSEGUE, no meio do maior entusiasmo, a mobilização dos esportistas paulistas.

Correio de S. Paulo, São Paulo, p.1, 20 jul. 1932.

REGIMENTO Esportivo. Diário Nacional, São Paulo, p.2, 27 set. 1932.

REIS, Lucas. Futebol e revolução. Folha de S. Paulo, 08 jul. 2012. Caderno de esporte, p.2. Disponível em: https://www1.folha.uol.com.br/fsp/esporte/53383-artilharia.shtml. Acesso em 05 abr. 2020.

ROSEGUINI, G.; OUTEIRAL, M. Friedenreich: o craque que foi para guerra. [vídeo] São Paulo: Globo Esporte, 2018. Disponível em: https://www.youtube.com/ watch?v=cqxXbjmL350. Acesso em: 05 abr. 2020.

SANTOS, Marco Cabral dos; MOTA, André. São Paulo 1932: memória, mito e identidade. São Paulo: Alameda, 2010. 
SEVCENKO, Nicolau. Orfeu extático na metrópole: São Paulo, sociedade e cultura nos frementes anos 20. São Paulo: Companhia das Letras, 1992.

TAMBÉM LUTARAM os atletas em 1932. Diário da Noite, São Paulo, p.4, 09 jul. 1954.

VEIGA, Edison. Os homens comuns da guerra paulista. O Estado de S. Paulo, 09 jul. 2015. Blog Paulistices, cultura geral e curiosidades. Disponível em: https://sao-paulo.estadao.com. br/blogs/edison-veiga/os-homens-comuns-da-guerra-paulista. Acesso em 05/04/2020.

VEIO de Eleutério e trouxe boas notícias do Batalhão Esportivo. A Gazeta, São Paulo, p.1, 26 ago. 1932.

OS VOLUNTÁRIOS do Batalhão Esportivo reclamam os seus vencimentos. A Gazeta, São Paulo, p.3, 12 out. 1932.

VOLUNTÁRIOS que regressam. Correio de S. Paulo, São Paulo, p.1, 04 out. 1932.

WEINSTEIN, Barbara. The color of modernity: São Paulo and the making of race and nation in Brazil. Durham: Duke University, 2015. 
Abstract: The São Paulo State Department of Physical Education (DEF-SP) suspended its regular activities during the 1932 civil war and started to recruit athletes for the armed struggle. This study describes the participation of the DEFSP in the war, analyzes the narratives published by São Paulo's press about athletes' enlistment and participation, and identifies strategies employed to establish a memory about the event. We found that the DEF-SP centralized the actions of sports clubs and federations to provide support to the armed struggle and form three paramilitary units. The state's press attributed physical and moral values to sport to foster regionalist feelings among the population and affirm a regional (paulista) identity. Two years after the armistice, the First Sports Battalion Civic Association was founded to create a triumphalist memory about the athletes' armed uprising.

Keywords: War. Sports. Memory. Social identity.

Resumen: El Departamento de Educación Física del Estado de São Paulo (DEFSP) suspendió sus actividades oficiales durante la guerra civil brasileña de 1932 y empezó a reclutar deportistas para la lucha armada. La investigación tuvo como objetivo describir la participación del DEF-SP en la guerra, analizar las narrativas publicadas por la prensa de São Paulo sobre el alistamiento y la participación de los deportistas e identificar las estrategias emprendidas para crear una memoria para el evento. Se concluye que DEF-SP centralizó las acciones de clubes y federaciones deportivas para fornecer apoyo a la lucha armada y formar tres tropas paramilitares. La prensa atribuyó valores físicos y morales al deporte para fomentar sentimientos regionalistas entre la población y afirmar una identidad regional paulista. Dos años después del armisticio, se fundó la Asociación Cívica Primer Batallón Deportivo para establecer una memoria triunfalista para el levante armado de los deportistas.

Palabras clave: Guerra. Deportes. Memoria. Identidad social. 


\section{LICENÇA DE USO}

Este é um artigo publicado em acesso aberto (Open Access) sob a licença Creative Commons Atribuição 4.0 Internacional (CC BY 4.0), que permite uso, distribuição e reprodução em qualquer meio, desde que o trabalho original seja corretamente citado. Mais informações em: http://creativecommons.org/licenses/by/4.0

\section{CONFLITO DE INTERESSES}

Os autores declararam que não existe nenhum conflito de interesses neste trabalho.

\section{CONTRIBUIÇÕES AUTORAIS}

André Dalben: Responsável pela orientação acadêmica de Lucas Polli da Palma. Contribuiu no levantamento da bibliografia empregada na pesquisa, na análise dos dados e na escrita do artigo.

Lucas Polli da Palma: Responsável pelo levantamento e fichamento das fontes históricas empregadas na pesquisa. Contribuiu no levantamento da bibliografia, na análise dos dados e na escrita do artigo.

\section{FINANCIAMENTO}

O presente trabalho foi realizado sem o apoio de fontes financiadoras.

\section{COMO REFERENCIAR}

DALBEN, André; POLLI DA PALMA, Lucas. A mobilização esportiva promovida pelo Departamento de Educação Física do Estado de São Paulo na guerra civil de 1932. Movimento (Porto Alegre), v.27, p.e27034, jan./dez. 2021. Disponível em: https://seer.ufrgs.br/Movimento/article/view/101640. Acesso em: [dia] [mês abreviado]. [ano]. DOI: https://doi.org/10.22456/1982-8918.101640

\section{RESPONSABILIDADE EDITORIAL}

Alex Branco Fraga*, Elisandro Schultz Wittizorecki, Ivone Job*, Mauro Myskiw*, Raquel da Silveira*

*Universidade Federal do Rio Grande do Sul, Escola de Educação Física, Fisioterapia e Dança, Porto Alegre, RS, Brasil. 